\title{
Prevalence of gestational diabetes mellitus using IADPSG and DIPSI criteria: a cross-sectional study
}

\author{
Trupti C. Ruge*, Nisha Kanchana
}

Department of Obstetrics and Gynaecology, Navodaya Medical College, Raichur, Karnataka, India

Received: 19 February 2020

Revised: 16 April 2020

Accepted: 22 April 2020

\author{
*Correspondence: \\ Dr. Trupti C. Ruge, \\ E-mail: truptiruge87@gmail.com
}

Copyright: (c) the author(s), publisher and licensee Medip Academy. This is an open-access article distributed under the terms of the Creative Commons Attribution Non-Commercial License, which permits unrestricted non-commercial use, distribution, and reproduction in any medium, provided the original work is properly cited.

\section{ABSTRACT}

Background: Considering the magnitude of adverse pregnancy outcomes related to gestational diabetes, the present study was undertaken to find out the prevalence of gestational diabetes mellitus using the international association of diabetes in pregnancy study groups criteria (IADPSG) and diabetes in pregnancy study group India (DIPSI) criteria to ascertain whether the present practice of diagnosing GDM by the guidelines recommended by DIPSI 21 based on WHO criterion of $2-\mathrm{h} P G \geq 140 \mathrm{mg} / \mathrm{dL}$ can still be followed in this study settings or adopt IADPSG recommendation.

Methods: This study was done at Antenatal Clinic, department of obstetrics and gynecology, KLES Dr Prabhakar Kore Hospital, Belgaum from January 2013 to December 2013. A total of 225 pregnant women between 24 to 28 weeks gestations were studied. Diagnosis and the prevalence of GDM were assessed by applying both DIPSI and IADPSG criteria.

Results: Most of the women $(58.11 \%)$ were between 22 to 25 years and the mean age was $23.78 \pm 3.38$ years. Based on the IADPSG criteria, the prevalence of GDM was $19.11 \%$ and by applying DIPSI criteria, prevalence of GDM was $16.89 \%$. The difference in diagnostic capability between IADPSG and DIPSI was found to be $2.8 \%$ and the kappa statistics showed good strength of agreement between the two tests $(p>0.302$; Kappa=0.774).

Conclusions: It was concluded that, the diagnosis GDM based on DIPSI is as effective as IADPSG criteria. Further, in resource poor countries like India, DIPSI procedure would be used with an advantage of being less costly and without compromising the clinical equipoise.

Keywords: Diabetes in pregnancy study group of India criteria, Gestational diabetes mellitus, International association of diabetes in pregnancy study groups criteria

\section{INTRODUCTION}

In most Asian countries, the economic prosperity is increasing. This has implications for the way people live, what they eat and patterns of disease they experience. China, India and several South East Asian nations are experiencing a rise in obesity and diet related noncommunicable diseases. Type 2 diabetes mellitus has been documented to be increasing in Asia, although the increase seems to be greater in South Asia compared to East and South East Asia. ${ }^{1,2}$ It was estimated that globally in 2011, 366 million people were living with diabetes.
This is predicted to rise to 552 million people by 2030 with half of these living in Asia. ${ }^{3}$ Gestational diabetes mellitus (GDM) is defined as glucose intolerance first discovered in pregnancy. It is carbohydrate intolerance with onset or recognition during pregnancy. ${ }^{4}$

Depending on the diagnostic criteria used and the population screened, the prevalence of GDM ranges from 1.1 to $25.5 \%$ of pregnancies in the United States. ${ }^{5-9}$ In 2009 the centers for disease control and prevention reported a prevalence of $4.8 \%$ of diabetes in pregnancy. An estimated $0.5 \%$ of these cases likely represented 
women with pregestational diabetes. Data from the international hyperglycemia and adverse pregnancy outcome (HAPO) study indicate that $6.7 \%$ of the women met a fasting plasma glucose threshold of $95 \mathrm{mg} / \mathrm{dL}(5.3$ $\mathrm{mmol} / \mathrm{L})$, which is in keeping with the Carpenter and Coustan (CC) criteria that are in common practice in North America. ${ }^{7,9}$ In contrast, $17.8 \%$ of women were diagnosed with GDM using the international association of diabetes in pregnancy study groups (IADPSG) criteria in which lower glucose thresholds are proposed to diagnose GDM. ${ }^{5,10}$ The prevalence of GDM in India varies from 3.8 to $21 \%$ in different parts of the country, depending on geographical locations and diagnostic methods used. ${ }^{11-14}$

Insulin is detectable in fetal pancreas as early as nine weeks after conception. ${ }^{15}$ An increase in beta cell mass and insulin secretion in the fetus occurs by the $16^{\text {th }}$ week of gestation, in response to maternal hyperglycemia. ${ }^{16}$ The priming of the fetal beta cells may account for the persistence of fetal hyperinsulinemia throughout pregnancy and risk of accelerated fetal growth, even when the mother enjoys good metabolic control in later pregnancy. ${ }^{17,18}$ This necessitates performing the test procedures to diagnose GDM in the first trimester itself. Further, early detection and care results in a better fetal outcome. ${ }^{19}$

Studies conducted in different populations and with different methodologies, consistently reported an increase in GDM in all race/ethnicity groups, suggesting that there is an increase in GDM prevalence. A true increase in the prevalence of GDM aside from its adverse consequences for the infant in the new-born period might reflect or contribute to the ongoing pattern of increasing diabetes and obesity.

This implies that Universal screening and care of women with GDM is of paramount public health priority in high risk population for GDM and diabetes like Asian Indians, rather than risk factor screening. In this aspect, except the existing diagnostic criterion of World Health Organization (WHO) 2-h plasma glucose (PG) $\geq 140$ $\mathrm{mg} / \mathrm{dL}$ with $75 \mathrm{~g}$ oral glucose load, other diagnostic criteria are country specific or recommended by various associations. $^{20}$

Currently diabetes in pregnancy study group of India (DIPSI) criteria is being used commonly in the community as it is difficult to get the patients in fasting state but since in a tertiary care hospital where patients come for regular antenatal follow up it is possible for them to report back during 24 to 28 weeks in a fasting state therefore this criteria can also be adopted to find the prevalence of GDM. ${ }^{21}$

Recently, based on the hyperglycemia and adverse pregnancy outcome (HAPO) study, the international association of diabetes and pregnancy study groups (IADPSG) consensus panel recommended that GDM can be diagnosed, if any one value of fasting plasma glucose (FPG), 1-h and 2-h plasma glucose (PG) concentrations meet or exceed $92 \mathrm{mg} / \mathrm{dL}, 180 \mathrm{mg} / \mathrm{dL}$ and $153 \mathrm{mg} / \mathrm{dL}$ respectively, with $75 \mathrm{~g}$ oral glucose tolerance test (OGTT) ${ }^{7,10}$ India one of the most populous countries in the world was not a part of the HAPO study.

The IADPSG recommends that the diagnosis of GDM be made when any of the following 75 grams of oral glucose, fasting, 1 hour, 2-hour oral glucose tolerance test (OGTT) thresholds are met or exceeded; fasting 92 $\mathrm{mg} / \mathrm{dL}, 1$ hour $180 \mathrm{mg} / \mathrm{dL}$, or 2 hours $153 \mathrm{mg} / \mathrm{dL} .^{10,22}$

Considering the magnitude of adverse pregnancy outcomes related to gestational diabetes the present study was undertaken to find out the prevalence of gestational diabetes mellitus using the IADPSG and DIPSI criteria to ascertain whether the present practice of diagnosing GDM by the guidelines recommended by DIPSI based on WHO criterion of $2-\mathrm{h} P G \geq 140 \mathrm{mg} / \mathrm{dL}$ can still be followed in this settings or adopt IADPSG recommendation. ${ }^{10,21,22}$

\section{METHODS}

This cross-sectional study was conducted in the department of obstetrics and gynecology, KLE'S Dr. Prabhakar Kore Hospital and Medical Research Centre, Belgaum from January 2013 to December 2013. A total of 225 pregnant women between 24 to 28 weeks of gestation registered at antenatal clinic were studied. Known diabetic women and not consenting to participate in the study were excluded from the study. Prior to the commencement, ethical clearance was obtained from the Institutional Ethical committee, Jawaharlal Nehru Medical College, Belgaum, India.

The eligible women were explained about the nature of the study and a written informed consent was obtained. After the enrollment demographic data, obstetric history and current pregnancy details were obtained. Further these women were subjected to clinical examination.

Under aseptic precautions, $2 \mathrm{~mL}$ of venous blood sample was drawn in the fasting state. Further these women were given $75 \mathrm{~g}$ oral glucose and their one hour and two hours venous blood samples were drawn. The plasma glucose was estimated in the hospital laboratory by glucose oxidase peroxidase (GOD-POD) method. Diagnosis and the prevalence of GDM were assessed by applying both DIPSI and IADPSG criteria. ${ }^{10,22}$

Based on IADPSG criteria GDM was diagnosed if one or more values equals or exceeds thresholds of fasting plasma glucose of $5.1 \mathrm{mmol} / \mathrm{L}(92 \mathrm{mg} / \mathrm{dL})$, one hour plasma glucose level of $10.0 \mathrm{mmol} / \mathrm{dL}(180 \mathrm{mg} / \mathrm{dL})$ and two hour plasma glucose level of $8.5 \mathrm{mmol} / \mathrm{L}(153$ $\mathrm{mg} / \mathrm{dL}){ }^{10,22}$ Using DIPSI criteria GDM was diagnosed if after 75 grams oral glucose two hour plasma glucose value exceeds above $140 \mathrm{mg} / \mathrm{dL}$. 


\section{Statistical analysis}

The categorical data was expressed as rates, ratios and proportions and continuous data was expressed as mean \pm standard deviation (SD). Difference in diagnostic capability between IADPSG and DIPSI was expressed in terms of percentage and Kappa statistics was used to evaluate the agreement. A probability value (' $p$ ' value) of less than or equal to 0.05 was considered as statistically significant.

\section{RESULTS}

The gestational age was 26 weeks in $26.67 \%$ of the women and mean gestational age was $26.25 \pm 2.70$ weeks. Majority of the women (74.22\%) had body mass index between 19.8 to $25.99 \mathrm{~kg} / \mathrm{m}^{2}$ and mean body mass index was $22.83 \pm 3.75 \mathrm{~kg} / \mathrm{m}^{2}$.

Table 1: Abnormal $75 \mathrm{~g}$ GTT at different intervals according to IADPSG criteria.

\begin{tabular}{|lll|}
\hline GDM $(\mathrm{mg} / \mathrm{dL})$ & \multicolumn{2}{l|}{ Distribution $(\mathbf{n}=\mathbf{2 2 5})$} \\
\hline Fasting $(\geq 92)$ & Frequency & Percent \\
\hline One hour $(\geq 180)$ & 21 & $9.33 \%$ \\
\hline Two hours $(\geq 153)$ & 20 & $8.89 \%$ \\
\hline
\end{tabular}

Table 2: Mean plasma glucose levels at different intervals.

\begin{tabular}{|lll|}
\hline \multirow{2}{*}{ Interval } & \multicolumn{2}{l|}{ Mean values $(\mathbf{n}=\mathbf{2 2 5})(\mathbf{m g} / \mathbf{d L})$} \\
\hline Fasting & 80.35 & SD \\
\hline One hour & 122.9 & 17.37 \\
\hline Two hours & 107.76 & 31.96 \\
\hline
\end{tabular}

The fasting, one hour and two hours plasma glucose levels were $\geq 92, \geq 180$ and $\geq 153 \mathrm{mg} / \mathrm{dL}$ in $9.33 \%, 8.99 \%$ and $7.56 \%$ of the women respectively (Table 1 ).

At same intervals the mean fasting plasma glucose levels were $80.35 \pm 17.37, \quad 122.90 \pm 31.96$ and $107.76 \pm 29.51$ $\mathrm{mg} / \mathrm{dL}$ respectively (Table 2).At different intervals, majority of abnormal cases were observed at fasting (5.78\%) followed by 1 hour (4.89) and 2 hours (2.67\%) (Table 3).
Table 3: Abnormal 75 g GTT at different intervals.

\begin{tabular}{|lll|}
\hline Intervals & Distribution $(\mathbf{n}=225)$ \\
\hline Fasting & Frequency & Percent \\
\hline 1 hour & 13 & $5.78 \%$ \\
\hline 2 hours & 11 & $4.89 \%$ \\
\hline Fasting + 1 hour & 6 & $2.67 \%$ \\
\hline Fasting + 2 hours & 2 & $0.89 \%$ \\
\hline 1 hour + 2 hour & 4 & $1.78 \%$ \\
\hline Fasting + 1 hour + 2 hours & 5 & $2.22 \%$ \\
\hline Normal & 2 & $0.89 \%$ \\
\hline Total & 182 & $80.89 \%$ \\
\hline
\end{tabular}

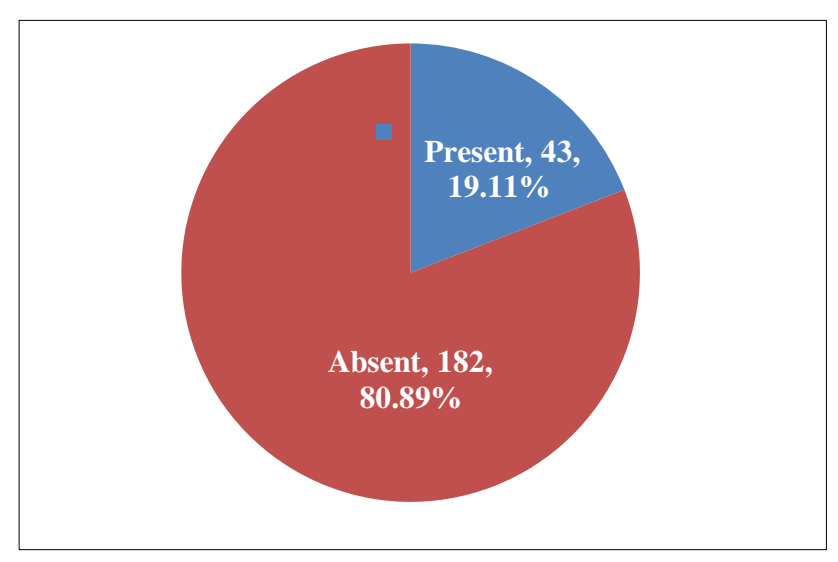

Figure 1: Prevalence of GDM based on IADPSG criteria.

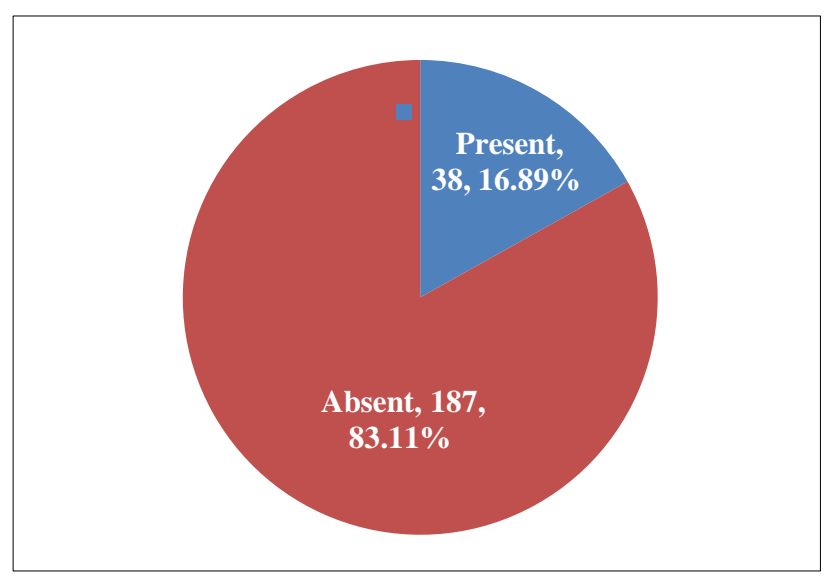

Figure 2: Prevalence of GDM based on DIPSI.

Table 4: Difference in diagnostic capability between IADPSG and DIPSI.

\begin{tabular}{|c|c|c|c|c|c|c|}
\hline \multirow{3}{*}{$\begin{array}{l}\text { GDM based on } \\
\text { DIPSI }\end{array}$} & \multicolumn{4}{|c|}{ GDM based on IADPSG } & \multirow{2}{*}{\multicolumn{2}{|c|}{ Total (n=120) }} \\
\hline & \multicolumn{2}{|c|}{ Present } & \multicolumn{2}{|c|}{ Absent } & & \\
\hline & No. & $\%$ & No. & $\%$ & No. & $\%$ \\
\hline Present & 33 & $86.84 \%$ & 5 & $13.16 \%$ & 38 & $16.89 \%$ \\
\hline Absent & 10 & $5.35 \%$ & 177 & $94.65 \%$ & 187 & $83.11 \%$ \\
\hline Total & 43 & $19.11 \%$ & 182 & $80.89 \%$ & 225 & $100.00 \%$ \\
\hline
\end{tabular}


Based on the IADPSG criteria, the prevalence of GDM was $19.11 \%$ (Figure 1) and by applying DIPSI criteria that is $\geq 140 \mathrm{mg} / \mathrm{dL}$ plasma glucose levels at two hours, prevalence of GDM was $16.89 \%$ (Figure 2). The difference in diagnostic capability between IADPSG and DIPSI was found to be $2.8 \%$ and the kappa statistics showed good strength of agreement between the two tests (Kappa $=0.774, \mathrm{p}>0.302)$ (Table 4).

Hence it may be concluded that, the diagnosis GDM based on DIPSI is as effective as IADPSG criteria.

\section{DISCUSSION}

In the present study the prevalence of GDM was $19.11 \%$ based on IADPSG criteria and $16.89 \%$ according to DIPSI criteria. There is wide variation in the prevalence of GDM in India. ${ }^{23}$ Earlier studies reported prevalence of $2 \%$ which rose to $7.62 \% .^{24,25}$ During 2002-2003, a random survey performed in various cities in India revealed prevalence of GDM as $16.2 \%$ in Chennai, $15 \%$ in Thiruvananthapuram, $21 \%$ in Alwaye, $12 \%$ in Bangalore, $18.8 \%$ in Erode and $17.5 \%$ in Ludhiana. ${ }^{26}$ An overall GDM prevalence of 16.55 per cent was observed. Another study done in Tamil Nadu during 2005-2007, GDM was detected in $17.8 \%, 13.8 \%$ and $9.9 \%$ of the women in urban, semi-urban and rural areas, respectively. ${ }^{12}$ The findings of the present study were consistent with the studies done in south India during the last decade. ${ }^{12}$ However the wide variation in the prevalence rates of GDM may be attributed to the use of different criteria for diagnosis, variation in geographical region and life style with lack of physical activity.

In the present study, fasting, one hour and two hours plasma glucose levels were $\geq 92, \geq 180$ and $\geq 153 \mathrm{mg} / \mathrm{dL}$ in $9.33 \%, 8.99 \%$ and $7.56 \%$ of the women respectively and at same intervals the mean fasting plasma glucose levels $80.35 \pm 17.37,122.90 \pm 31.96 \mathrm{mg} / \mathrm{dL}$ and $107.76 \pm 29.51$ $\mathrm{mg} / \mathrm{dL}$ respectively. Based on the IADPSG criteria,10,22 the prevalence of GDM $19.11 \%$ and by applying DIPSI criteria that is $\geq 140 \mathrm{mg} / \mathrm{dL}$ plasma glucose levels at two hours, prevalence of GDM was $16.89 \% .^{21}$ The difference in diagnostic capability between IADPSG and DIPSI was found to be $2.8 \% .^{10,21,22}$ However the concordance observed was statistically not significant and the kappa statistics showed good strength of agreement between the two tests $(p>0.302 ; p=0.302 ;$ Kappa $=0.774 ;$ SE of kappa $=0.056$; 95\% CI: From 0.665 to 0.883 ). These findings suggest that, to diagnose GDM, DIPSI procedure based on WHO criterion of $2-\mathrm{h} P G \geq 140 \mathrm{mg} / \mathrm{dL}$ is as effective as IADPSG criteria. ${ }^{10,21,22}$ Recently a similar study done in Chennai also found prevalence of GDM, as $13.4 \%$ and $14.6 \%$ using DIPSI and IADPSG criteria respectively. ${ }^{10,21,22}$ The difference in the diagnostic capability between IADPSG and DIPSI was $1.2 \%$ $(\mathrm{p}>0.02){ }^{10,21,22}$

The IADPSG recommendation requires estimation of plasma glucose in three blood samples after administrating $75 \mathrm{~g}$ oral glucose load whereas, DIPSI criterion requires one blood sample drawn at 2-h for estimating the plasma glucose yielding to higher costs. $^{10,22}$ Further DISPI requires little preparation, without requiring the prior interposition of the screening test and hence it could be applied at the community levels. ${ }^{21}$ Thus, DIPSI procedure would still serve the purpose of implementing public health program to diagnose GDM in the community. ${ }^{21}$

Surprisingly similar results were found on the comparison of IADPSG and the WHO criteria to diagnose GDM. ${ }^{10,22,27}$ A maiden study compared the IADPSG and the WHO criteria to diagnose GDM in Chennai, India. ${ }^{10,22,27}$ The study reviewed the retrospective data of 1351 pregnant women who underwent screening for GDM at four selected diabetes centers at Chennai (three private and one government). All women underwent an oral glucose tolerance test using $75 \mathrm{~g}$ glucose load and fasting, 1-hour, and 2-hour samples were collected. The IADPSG and WHO criteria were compared for diagnosis of GDM. ${ }^{10,22,27}$ A total of 839 women had GDM by either the IADPSG10,22 or the WHO criteria, of whom the IADPSG criteria identified 699 and the WHO criteria also identified 699 women as having GDM. ${ }^{10,22,27}$ However, only 599/839 women $(66.6 \%)$ were identified by both criteria. Thus, 140/839 women $(16.7 \%)$ were missed by both the IADPSG and the WHO criteria. ${ }^{10,22,27} 687 / 699(98.2 \%)$ of the women with GDM were identified by the WHO criteria. ${ }^{27}$ In contrast, each value of IADPSG criteria10,22 i.e., fasting, 1 hour, and 2 hour identified only $12.5 \%, 14 \%$, and $22 \%$, respectively. A single WHO cut-point of 2 hours $>140$ $\mathrm{mg} / \mathrm{dl}$ appears to be suitable for large-scale screening for GDM in India and other developing countries.

The WHO first proposed criteria for GDM using a $75 \mathrm{~g}$ OGTT in the 1980 s. ${ }^{28,29}$ In its technical report published in 1994, it defined GDM as DM first recognized during pregnancy, and gestational impaired glucose tolerance (GIGT) as IGT first recognized during pregnancy. ${ }^{30}$ In 1998, WHO recommended new criteria. ${ }^{31}$ With regard to GDM, pregnant women who met the WHO criteria27 for DM or IGT were classified as having GDM and, therefore, the term GIGT disappeared. Some studies have been published taking FPG $>126 \mathrm{mg} / \mathrm{dl}$ as the criteria for GDM. $^{32}$ However, the more recent studies have altogether ignored the FPG criteria and have used only the 2 -hour $>140 \mathrm{mg} / \mathrm{dl}$ criteria of the WHO. ${ }^{33}$ When the ADA lowered the FPG to $100 \mathrm{mg} / \mathrm{dl}$ from the previous $110 \mathrm{mg} / \mathrm{dl}$ for diagnosis of impaired fasting glucose in non-pregnant adults, the FPG level of $126 \mathrm{mg} / \mathrm{dl}$ in pregnancy started looking too high and most people just chose to ignore the FPG level for the diagnosis of GDM. However, till date, there is no official recommendation from WHO to drop FPG criteria and to follow only the 2$\mathrm{h}$ value of $140 \mathrm{mg} / \mathrm{dl} .{ }^{34}$

It appears an anomaly that in the WHO criteria, the fasting cut-off had been set at $126 \mathrm{mg} / \mathrm{dl}$ which is 
diagnostic of diabetes in non-pregnant adults, whereas the 2-h cut-off was set at $140 \mathrm{mg} / \mathrm{dl}$, which is the diagnostic cut-point for IGT in non-pregnant adults. ${ }^{27}$ Probably because of this inherent contradiction in the diagnostic criteria, the fasting values in the WHO criteria are not particularly useful to diagnose GDM and this might explain why the WHO 2-hour value alone picked up over $98 \%$ of all cases diagnosed by both fasting and 2-hour WHO criteria in this study. ${ }^{27}$ Another point to be noted is that if a pregnant woman has a FPG $\geq 126 \mathrm{mg} / \mathrm{dl}$, it is considered overt diabetes complicating pregnancy, and not as GDM, by the IADPSG criteria. ${ }^{10,22}$

Another issue of concern is whether too many women would get diagnosed as GDM because of the low FPG cut-off in the IADPSG criteria. $^{10,22}$ Indeed, of the 88 women who were diagnosed as GDM by virtue of their FPG abnormality alone using IADPSG criteria, only 30 $(34 \%)$ were classified as GDM by the WHO criteria. ${ }^{10,22,27}$ A similar comparison with those with GDM according to the IADPSG 1-hour cut-off value showed that only 47/98 (48\%) had GDM by WHO criteria. ${ }^{27}$ It is thus possible that by reducing the FPG cutpoint to $92 \mathrm{mg} / \mathrm{dl}$, we could be over-diagnosing GDM in normal pregnant women. This could lead to overloading of the health systems in many countries. ${ }^{35}$

Earlier reports have shown that the sensitivity of the 2hour value in the glucose tolerance test (GTT) is much higher than the fasting plasma glucose among nonpregnant Indian adults. ${ }^{34}$ Thus, it is reasonable to assume that since the IADPSG has raised the 2-hour value in the IADPSG to $153 \mathrm{mg} / \mathrm{dl}$, many cases of GDM could be missed. ${ }^{35}$

The finding of the present study were in agreement with a study done in Chennai despite the methodological differences that is, difference in study design, criteria used to diagnose GDM and sample size. ${ }^{35}$

Overall, the present study showed that, DIPSI procedure based on WHO criterion of 2-hour PG $\geq 140 \mathrm{mg} / \mathrm{dL}$ would be cost-effective without compromising the clinical equipoise. ${ }^{27}$ However the limitations of the study were the study did not consider the diagnostic capability in different confounding variable such as maternal age, parity and obesity as it was beyond the scope of this study. However, association between parity and diabetes is strongly linked to obesity and age. Women with higher parity frequently are older and more obese. Obesity is an intermediate outcome in the causal pathway between parity and gestational diabetes mellitus, probably a mediating factor. However, age is a potential confounder in the association between parity and gestational diabetes mellitus. ${ }^{36}$ Hence further studies with large sample size considering the age, parity and obesity would enlighten the role of DIPSI in the diagnosis of GDM.

One of the limitations of the study is that with this present data, authors cannot conclude whether IADPSG or DIPSI criteria is better for Indian pregnant women as authors do not have data on the maternal and fetal outcomes which was beyond the scope of this study. ${ }^{10,20,21}$ In the absence of the outcome data, which however, was beyond the purview of the study, it was not possible to comment on the suitability of diagnosing GDM by either of the two criteria in this population. Nonetheless, this study compared the ease of use of two criteria in the population studied. Future studies should compare the outcomes of the GDM cases diagnosed by IADPSG and DIPSI criteria as this would provide the final answer as to which criteria is more suitable for Indians. ${ }^{10,21,22}$

\section{CONCLUSION}

From the present study, it was concluded that, the diagnosis GDM based on DIPSI is as effective as IADPSG criteria. Further, in resource poor countries like India, DIPSI procedure would be used with an advantage of being less costly and without compromising the clinical equipoise.

\section{Funding: No funding sources}

Conflict of interest: None declared

Ethical approval: The study was approved by the Institutional Ethics Committee

\section{REFERENCES}

1. Chan J, Malik V, Jia W, Kadowaki T, Yajnik C, Yoon K, et al. Diabetes in Asia epidemiology, risk factors and pathophysiology. JAMA. 2009;301:2129-41.

2. Danaei G, Finucane MM, Lu Y, Singh GM, Cowan MJ, Paciorek CJ, et al. National, regional, and global trends in fasting plasma glucose and diabetes prevalence since 1980: systematic analysis of health examination surveys and epidemiological studies with 370 country-years and 2.7 million participants. Lancet. 2011;378:31-40.

3. Hirst JE, Raynes-Grenow CH, Jeffery HE. A systematic review of trends of gestational diabetes mellitus in Asia. J Diabetes Asia Study Group. 2012;3(4):1-12.

4. Balsells M, Garcia-Patterson A, Gich I, Corcoy R. Maternal and fetal outcome in women with type 2 versus type 1 diabetes mellitus: a systematic review and metaanalysis. J Clin Endocrinol Metab. 2009;94(11):4284-91.

5. Hartling L, Dryden DM, Guthrie A, Muise M, Vandermeer B, Aktary WM, et al. Screening and diagnosing gestational diabetes mellitus. Rockville (MD): Agency for Healthcare Research and Quality (US); 2012.

6. National Diabetes Data Group: Diabetes in America, edn2. Bethesda, MD: National Institutes of Health, National Institute of Diabetes and Digestive and Kidney Diseases, NIH Publication No. 1995;14951468. 
7. HAPO study cooperative research group. Metzger B, Lowe L, et al. Hyperglycemia and Adverse Pregnancy Outcomes. N Eng J Med. 2008;358(19):1991-2002.

8. American Diabetes Association. Position statement: standards of medical care in diabetes - 2012. Diabetes Care. 2012;35(Suppl 1):S11-63.

9. Carpenter MW, Coustan DR. Criteria for screening tests for gestational diabetes. Am J Obstet Gynecol. 1982;144(7):768-73.

10. International association of diabetes and pregnancy study groups (IADPSG) recommendations on the diagnosis and classification of hyperglycemia in pregnancy. IADPSG consensus panel. Diabetes Care. 2010;33:676-82.

11. Seshiah V, Balaji V, Madhuri S Balaji, Panneerselvam A, Kapur A. Pregnancy and Diabetes Scenario around the World: India. Int J Gynaecol Obstet. 2009;104:S35-8.

12. Seshiah V, Balaji V, Madhuri S Balaji, Panneerselvam A, Arthi T, Thamizharasi M, et al. Prevalence of GDM in South India (Tamil Nadu) - A Community based study. JAPI. 2008;56:329-33.

13. Swami SR, Mehetre R, Shivane V, Bandgar TR, Menon PS, Shah NS. Prevalence of carbohydrate intolerance of varying degrees in pregnant females in western India (Maharashtra) - a hospital-based study. J Indian Med Assoc. 2008;106:712-4.

14. Divakar H, Tyagi S, Hosmani P, Manyonda IT. Diagnostic criteria influence prevalence rates for gestational diabetes: implications for interventions in an Indian pregnant population. Perinatol. 2008; 10:155-61.

15. Schmidt MI, Duncan BB, Reichelt AJ, Branchtein L, Matos MC, Costa E, et al. For the Brazilian gestational diabetes study group. Gestational diabetes mellitus diagnosed with a 2-h 75-g oral glucose tolerance test and adverse pregnancy outcomes. Diabetes Care. 2001;24(7):1151-5.

16. Kousta E, Lawrence NJ, Penny A, Millauer BA, Robinson S, Dornhorst A, et al. Implications of new diagnostic criteria for abnormal glucose homeostasis in women with previous gestational diabetes. Diabetes Care. 1999;22(6):933-7.

17. Sermer M, Naylor CD, Farine $D$, Kenshole AB, Ritchie JW, Gare DJ, et al. The Toronto Tri-Hospital gestational diabetes project. A preliminary review. Diabet Care. 1998;21 Suppl 2:33-42.

18. Metzger BE, Lowe LP, Dyer AR, Trimble ER, Chaovaridr U, Coustan DR, et al. HAPO Study Cooperative Research Group. Hyperglycemia and adverse pregnancy outcomes. $N$ Engl J Med. 2008;358(19):1991-2002.

19. Franks PW, Looker HC, Kobes S, Touger L, Tataranni PA, Hanson RL, et al. Gestational Glucose tolerance and risk of type 2 diabetes in Young Pima Indian Offspring. Diabet. 2006;55(2):460-5.

20. Balaji V, Balaji M, Anjalakshi C, Cynthia A, Arthi T, Seshiah V. Diagnosis of gestational diabetes mellitus in Asian-Indian women. Indian J Endocrinol Metab. 2011;15(3):187-90.

21. Seshiah V, Sahay BK, Das AK, Shah S, Banerjee S, Rao PV, et al. Gestational diabetes mellitus - Indian guidelines. JIMA. 2009; 107:799-806.

22. American Diabetes Association. Standards of medical care in diabetes - 2011. Diabet Care. 2011;34(Suppl1):S15.

23. Rajput R, Yadav Y, Nanda S, Rajput M. Prevalence of gestational diabetes mellitus and associated risk factors at a tertiary care hospital in Haryana. Indian J Med Res. 2013;137(4):728-33.

24. Agarwal S, Gupta AN. Gestational diabetes. J Assoc Physicians India. 1982;30:203-5.

25. Narendra J, Munichoodappa C, Gurudas A, Ramprasad AV, Madhav T, Vijayalakshmi, et al. Prevalence of glucose intolerance during pregnancy. Int J Diab Dev Countries. 1991;11:2-4.

26. Verma AK, Singh B, Mengi V. Gestational diabetes in rural women of Jammu. Indian J Comm Med. 2008;33:54-5.

27. Alberti K, Zimmett P. Definition, diagnosis and classification of diabetes mellitus and its complications, Part 1: diagnosis and classification of diabetes mellitus provisional report of a WHO consultation. Diabet Med. 1998;15:539-53.

28. WHO expert committee on diabetes mellitus: Second report. World Health Organ Tech Rep Ser. 1980;646:1-80.

29. World Health Organization Study Group on Diabetes mellitus. Technical Report Series, No. 727., WHO, Geneva; 1988.

30. World Health Organization. Prevention of diabetes mellitus. World Health Organ Tech Rep Ser 1994;844:11-35.

31. World Health Organization. Definition, diagnosis and classification of diabetes mellitus and its complications: report of a WHO consultation. Part 1, Diagnosis and classification of diabetes mellitus. WHO. 1999.

32. Sugaya A, Sugiyama T, Nagata M, Toyoda N. Comparison of the validity of the criteria for gestational diabetes mellitus by WHO and by the Japan society of obstetrics and gynecology by the outcomes of pregnancy. Diabetes Res Clin Pract. 2000;50:57-63.

33. Seshiah V, Balaji V, Balaji MS, Sanjeevi CB, Green A. Gestational diabetes mellitus in India. J Assoc Physicians India. 2004;52:707-11.

34. Deepa R, Shanthi Rani S, Premalatha G, Mohan V. Comparison of ADA 1997 and WHO 1985 criteria for diabetes in south Indians: The Chennai Urban Population Study. American Diabetes Association. Diabet Med. 2000;17:872-4.

35. Nallaperumal S, Bhavadharini B, Mahalakshmi MM, Maheswari K, Jalaja R, Moses A, et al. Comparison of the world health organization and the International association of diabetes and pregnancy study groups criteria in diagnosing gestational diabetes mellitus in 
South Indians. Indian J Endocr Metab. 2013;17:9069.

36. Dode MA, de Oliveira S, Dos SI. Non classical risk factors for gestational diabetes mellitus: a systematic review of the literature. Cadernos de Saúde Púb. 2009;25(3):S341-59.
Cite this article as: Ruge TC, Kanchana N.

Prevalence of gestational diabetes mellitus using IADPSG and DIPSI criteria: a cross-sectional study.

Int J Reprod Contracept Obstet Gynecol

2020;9:2408-14. 